\title{
Which border taxes? Origin and destination regimes with fiscal competition in output and emission taxes*
}

\author{
Helmuth Cremer \\ University of Toulouse \\ (IDEI and GREMAQ) \\ Toulouse, France \\ Firouz Gahvari \\ Department of Economics \\ University of Illinois at Urbana-Champaign \\ Urbana, IL 61801, USA \\ June 2003 \\ This version, April 2005
}

*We thank the referees and particularly the editor, Robin Boadway, for their constructive comments. 


\begin{abstract}
This paper posits a two-stage game in tax regime and tax rates to study the property of second-best emission and output taxes in a two-country world with an atmospheric externality. It shows that (i) either the destination-destination or the origin-origin tax regime may constitute the subgame perfect Nash equilibrium of this game; (ii) either regime may Pareto-dominate the other; (iii) it is possible to have a prisoner's dilemma game where the origin-origin regime Pareto-dominates but the choice of the destination regime is the dominant strategy for each country. Other results include (iv) Under origin-origin regime: the output tax is used for fiscal competition; the emission tax is set at a rate equal to the (national) marginal social damage of emissions; and public goods are provided sub-optimally. (v) Under destination-destination regime: the output tax is ineffective as an instrument for fiscal competition; the emission tax is used not only for combating pollution but also for tax competition; the tax is set at a rate below the (national) marginal social damage of emissions; emissions are pushed above their closed-economy level; the provision of public goods are optimal.

JEL classification: H21; H23; H73; H87; F15
\end{abstract}

Keywords: Global externality; emission taxes; output taxes; tax competition; destination regime; origin regime. 


\section{Introduction}

In closed economies, when pollution is the only source of market failure, the design of corrective taxes is straightforward. If there are no distortionary taxes in the economy, the tax on emissions should reflect the social marginal damage; and the price of the output (which incorporates both emissions and output taxes) ought simply to cover its marginal environmental cost in addition to private costs. Moreover, the two objectives can be attained using emission taxes alone. In the presence of distortionary taxes, optimal tax rules follow the "principle of targeting": Emission taxes are used for correcting the externalities (on both dimensions), and output taxes are levied for optimal tax considerations (i.e., to collect tax revenue and possibly to redistribute). ${ }^{1}$

Much of the debate about environmental policies these days is a global debate. ${ }^{2}$ One reason for this is that there are serious pollution problems that have a worldwide reach. This is true, first and foremost, for emissions of pollutants like $\mathrm{CO}_{2}$ associated with the greenhouse effect and global warming. They produce an atmosphere externality at the global level. Other types of emissions like $\mathrm{SO}_{2}$ have a more "local" character. Yet, even these do not wait for custom clearance to travel across national boundaries! A second important reason why environmental policy is a global issue is that in many instances the pollution remedies themselves introduce an additional source of externality between countries. We have in mind fiscal externalities that arise when the value of one country's tax instrument affects the welfare of another country's residents by changing their consumer or producer prices, and their government's tax revenues (but that neither

\footnotetext{
${ }^{1}$ This instrument separability rests on weak separability of preferences between emissions and other goods. See, Cremer and Gahvari (2001) who study the problem of the design of an integrated system of second-best emission and output taxes in a closed economy setting.

${ }^{2}$ Copeland and Taylor (1995) motivate trade through income differences and show that trade worsens the environment by making rich countries specialize in production of clean goods and poor countries (with less stringent regulations) in dirty goods. They generalize their setup in Antweiler et al. (2001) by including factor abundance in determining trade. There are also papers that study the impact of trade on environmental resources; see, e.g., Chichilinisky (1994) and Karp et al. (2001) who build models of North-South trade and motivate trade through differences in property rights.
} 
country takes the external effects of its fiscal policies into account in its optimization problem). Put differently, environmental levies may be subject to fiscal competition just like any other form of taxation. ${ }^{3}$

An important issue in designing environmental taxes in open economies is that of the choice between "origin" and "destination" principles of taxation. Under the origin principle, the purchasers (regardless of where they come from) pay the tax of the country in which the good is produced; under the destination principle, the purchasers (whether they buy the home- or foreign-produced good) pay the tax of the country in which they reside. As far as environmental levies are concerned, emission taxes are almost by definition origin-based taxes. The output tax, on the other hand, can be origin- or destination-based (just like any other commodity tax). The literature contains studies that compare the two regimes with respect to the properties of equilibrium policies. However, none are in the context of environmental taxation and particularly not when the interaction between emission and output taxes takes the center stage. Moreover, the comparisons are typically carried out for given tax regimes. It is the purpose of this paper to attempt to close these two gaps. ${ }^{4}$

We study the design of second-best output and emissions taxes in a global economy with an atmospheric externality, while endogenizing the choice of the output tax regime. ${ }^{5}$ We do this by considering the choice of the tax regime and the tax rates (output and emission) as a sequential game. In the first stage, the countries simultaneously choose

\footnotetext{
${ }^{3}$ See Mintz and Tulkens (1986) and Kanbur and Keen (1993) for a discussion of issues pertaining to commodity tax competition. Cremer et al. (1996), Wilson (1999), Wellisch (2000) and Haufler (2001) present general surveys of the tax competition literature.

${ }^{4}$ Lockwood et al. (1994) derive an equivalence between the two systems based on fixed tax rates and uniform commodity taxes either within a country or across the two countries. Lockwood (1993) compares the two regimes in a setting where tax rates are determined endogenously as the outcome of a non-cooperative Nash game. He shows, through examples, that either origin or destination tax systems can result in higher welfare levels. Keen and Lahiri (1998) also examine this question but under imperfect competition. See Lockwood (2001) for other references.

${ }^{5}$ There are papers in the literature with transboundary pollution which emphasize strategic trade consideration; see, e.g., Conrad (1993), Barrett (1994), and Kennedy (1994). However, these papers are partial equilibrium in nature and model imperfectly competitive environments. As such, they do not explore the full interactions between tax competition and transboundary pollution.
} 
their output tax regime. Then, in the second stage, they (simultaneously) set their tax instruments given the first-stage-selected output tax regime. The subgame perfect Nash equilibrium of this game determines the countries' output tax regimes, and the values of their emission and output taxes. We posit a simple setting with two identical countries whose inhabitants consume a publicly-provided and two privately-provided goods: a non-polluting numeraire good and a polluting consumption good. Every consumer has an endowment of the numeraire good, some of which he consumes, spending the rest to purchase the polluting good and pay taxes.

Pollution $\left(\mathrm{CO}_{2}, \mathrm{SO}_{2}\right.$, etc.) is global and a by-product of production. The polluting good may be produced in different ways. Each procedure entails a different resource cost and a different emission level. A higher level of emission reduces the private (per unit) production costs of polluting goods. That is, the production costs of polluting goods are negatively related to their emissions. This is to capture the fact that technologies which cut emissions are more expensive to employ. ${ }^{6}$ Firms producing the polluting good operate in a competitive environment. It is produced, for a given unit cost of production, by a linear technology subject to constant returns to scale.

The polluting good is produced and consumed in both countries. To simplify the exposition, the demand for this good is assumed to be perfectly inelastic. ${ }^{7}$ While the physical characteristics of the home- and foreign-produced goods are identical, consumers have a preference for purchasing the home-produced goods. We model this by assuming that consumers experience a certain disutility when they consume one unit of the foreign-produced good. The extent of the disutility differs across consumers. Individuals have otherwise identical quasi-linear preferences.

We show that under the origin system of taxation, the output tax is used for fiscal

\footnotetext{
${ }^{6}$ Antweiler et al. (2001) allow for abatement and distinguish between scale of output and the intensity of polluting technologies in determining emissions, but their concern is not tax competition and public good provision.

${ }^{7}$ See Cremer and Gahvari (2004) for the analysis of the case where demand for the polluting good varies with its price.
} 
competition. As a result, the "rule" for the provisons of public good is distorted. This distortion is translated into an under-provision of public goods (as compared to its closed-economy level which is also the first-best level). With the availability of the output tax, the emission tax is used to curb emissions and set equal to the marginal social damage of emissions. Nevertheless, because the public good is provided suboptimally, emissions exceed their closed-economy level. Under the destination system of taxation, on the other hand, the output tax does not affect a country's export price and thus cannot be used for fiscal competition. This is good news for the provision of public goods which remains first-best optimal (both in terms of rule as well as level). The ineffectiveness of output taxes for fiscal competition leads to the use of emission taxes for this purpose; however. The emission tax rate is set at less than the marginal social damage of emissions, and emissions are pushed above their closed-economy level. ${ }^{8}$

Comparing the equilibria under origin-origin and destination-destination taxes directly, we thus have a suboptimal level of public good provision under the former, and an optimal level under the latter regime. On this score alone, the destination-destination regime is superior to origin-origin regime. However, the tax regimes' differential impacts on emission levels may reverse this ranking. While both regimes imply higher pollution levels than the closed-economy solution, either regime may result in a higher pollution level (as compared to the other). This suggests that for the origin-origin regime to Pareto dominate the destination-destination regime, it must necessarily result in a lower emission level. Nevertheless, when emission levels are lower under origin-origin regime, it is still possible that the destination-destination regime will be better. We present examples where one or the other tax system leads to higher environmental quality and overall welfare levels.

Finally, with respect to the equilibrium tax regime, we show that either the originorigin or the destination-destination regime may constitute the subgame perfect Nash

\footnotetext{
${ }^{8}$ The targeting issue has been noted in the literature; see, e.g., Barrett (1994). Again, this has been studied within a partial equilibrium framework with restricted instruments.
} 
equilibrium of the two-stage game in the tax regime and the tax rates. Interestingly, it is also possible to have a prisoner's dilemma game where the origin-origin regime Pareto-dominates but the choice of the destination regime is the dominant strategy for each country.

\section{The basics}

Consider two identical countries in isolation, each with a population size normalized at one. ${ }^{9}$ Their inhabitants consume three goods: one publicly-provided and two privatelyprovided goods. The publicly-provided good, $G$, is nonpolluting. Each country provides $G$ to its own residents only. One of the privately-provided good is the numeraire good which is also nonpolluting. The other privately-provided good, $x$, is polluting. The demand for this good is perfectly inelastic so that everyone consumes only one unit of it regardless of the price. ${ }^{10}$ Every consumer has an endowment of $m$ units of the numeraire good, some of which he consumes, spending the rest to purchase the polluting good. Production technologies are identical in both countries. The publicly-provided good is produced at a constant average and marginal cost which we can normalize at one. The polluting good may be produced in different ways. Each procedure entails a different resource cost and a different emission level. ${ }^{11}$ Specifically, assume that the resource cost of producing one unit of output $C(e)$, where $e$ denotes emission per unit of output in country $i$, is a continuously differentiable, decreasing and convex function of $e^{12}$ Firms producing the polluting good operate in a competitive environment. The good

\footnotetext{
${ }^{9}$ One need not distinguish between the two countries in this section. All variables indicate the values attained in each country.

${ }^{10}$ This assumption is adopted for analytical simplicity. Allowing for $x$ to depend negatively on price, does not change the main points of the paper. See Cremer and Gahvari (2004) who adopt this more general specification.

${ }^{11}$ This models situations where a polluting good may be produced through different production techniques, or using different polluting inputs where each particular input entails a different emission level. Different abatement techniques also imply that a unit of polluting good is associated with different emission levels.

${ }^{12}$ More precisely the assumption is that $C^{\prime}()<$.0 for all $e$ up to some limit $\bar{e}$, and that $C^{\prime}(\bar{e})=0$.
} 
is produced by an industry that is comprised of a fixed but sufficiently large number of identical firms. It is produced, for a given $C(e)$, by a linear technology subject to constant returns to scale.

Each country uses two (distortionary) tax instruments, output and emission taxes; lump-sum taxation is ruled out. ${ }^{13}$ The output tax is levied at $\tau$ (dollars) per unit on consumers and the emission tax at $t$ (dollars) per unit of emissions on firms. ${ }^{14}$ Tax revenues, from both sources, are used to finance the provision of the public good, $G$. Denote the consumer and the producer price of $x$ by $p$ and $q$. Given the constant returns to scale assumption, the firm's profit maximization problem is simply one of maximizing profits per unit of output. That is, the firm chooses $e$ to maximize

$$
q-C(e)-t e
$$

This yields

$$
-C^{\prime}(e)=t
$$

where the second-order condition $C^{\prime \prime}(e)>0$ is satisfied from the convexity of $C($.$) .$ Moreover, the zero-profit condition implies that

$$
\begin{aligned}
& q=C(e)-C^{\prime}(e) e, \\
& p=C(e)-C^{\prime}(e) e+\tau .
\end{aligned}
$$

Consumers have identical quasi-linear preferences. When they buy the home-produced goods, their preferences are represented by the indirect (conditional) utility function

$$
u=m-p+\phi(G)-\varphi(E),
$$

where

$$
E=2 e,
$$

\footnotetext{
${ }^{13}$ Again, allowing for lump-sum taxation does not change the message of the paper. See Cremer and Gahvari (2004) who formally discuss the implications of allowing for lump-sum taxes.

${ }^{14}$ It is natural to assume that the emission taxes are levied on firms. As to the commodity taxes, this is of no consequence for this section. However, with our emphasis on destination versus origin taxes, it is also natural to assume right from the outset that the output tax is levied on consumers.
} 
denotes global emissions. We assume that $\phi($.$) is a continuously differentiable, increasing$ and concave function of its argument while $\varphi($.$) is continuously differentiable, increasing$ and convex; that is, $\phi^{\prime}()>0,. \phi^{\prime \prime}()<$.0 and $\varphi^{\prime}()>0,. \varphi^{\prime \prime}()>$.0 .

\subsection{Optimal benchmark}

With identical consumers and countries, it is natural to adopt a utilitarian perspective on social welfare. It is plain that the globally optimal allocation is symmetric. The welfare of one country can then be measured by the utility of its representative individual. The optimum is characterized by maximizing equation (4) subject to a country's resource constraint, or equivalently its government budget constraint. Thus assume a "centralized authority" chooses $\tau$ and $t$ to maximize (4) subject to

$$
G=t e+\tau=p-C(e),
$$

where $p$ is related to $\tau$ by (3) and $e$ is determined by $t$ according to (1). The optimization problem must allow for a full accounting of the damage of emissions-including that imposed by one country on the other. This implies that $E$ varies with $e$ on the basis of (5). Solving the first-order conditions for this problem yields ${ }^{15}$

Proposition 1 Assume that countries set their environmental policies cooperatively. The optimal allocations, and the supporting prices and tax instruments, are characterized by equations (1), (3), (5), (6), and

\footnotetext{
${ }^{15}$ The Lagrangian associated with this problem is

$$
\Delta=m-[C(e)+t e+\tau]+\phi(G)-\varphi(2 e)+\lambda(t e+\tau-G),
$$
}

with the first-order conditions:

$$
\begin{aligned}
& \frac{\partial \Delta}{\partial \tau}=-1+\lambda=0 \\
& \frac{\partial \Delta}{\partial t}=e(\lambda-1)+\left[\lambda t-2 \varphi^{\prime}(E)\right] \frac{\partial e}{\partial t}=0 \\
& \frac{\partial \Delta}{\partial G}=\phi^{\prime}(G)-\lambda=0 .
\end{aligned}
$$




$$
\begin{aligned}
\phi^{\prime}(G) & =1, \\
-C^{\prime}(e) & =2 \varphi^{\prime}(E) .
\end{aligned}
$$

Observe that equation (7) determines the value of $G$ and equation (8) the value of $e$ (and $E$ ); they are determined independently of one another. ${ }^{16}$ The value of $p$ is then determined via equation (6), resulting in a value for $\tau$ from (3). The output tax here is thus non-distortionary. Equation (8) indicates that emission taxes are levied to achieve the Pigouvian rule of equalizing the private benefits of a marginal increase in emissions [reducing production costs by $-C^{\prime}(e)$ ] to its marginal global damage, $2 \varphi^{\prime}(E)$.

\subsection{Closed-economy allocations}

In characterizing the globally optimal allocation, we assumed that each country takes the damage its emissions impose on the other country fully into account. We now assume that governments choose the values of their fiscal instruments (which determine their emission levels) simultaneously and non-cooperatively. Their objective is to maximize the welfare of their own residents only. Solving the "best-reply" functions for the two countries, assuming a symmetric Nash-equilibrium, leads to ${ }^{17}$

\footnotetext{
${ }^{16}$ That the values of $G$ and $e$ are independent of one another, also implies that the optimal values of $\tau$ and $t$ (output and emission taxes) are independent of one another. This feature is due to the assumption of an inelastic demand for $x$. See Cremer and Gahvari (2001).

${ }^{17}$ The Lagrangian associated with one country's problem is

$$
\Delta=m-[C(e)+t e+\tau]+\phi(G)-\varphi(e+\hat{e})+\lambda(t e+\tau-G),
$$
}

where $\hat{e}$ is the other countries emission level treated as given. The first-order conditions are:

$$
\begin{aligned}
\frac{\partial \Delta}{\partial \tau} & =-1+\lambda=0 \\
\frac{\partial \Delta}{\partial t} & =e(\lambda-1)+\left[\lambda t-\varphi^{\prime}(E)\right] \frac{\partial e}{\partial t}=0 \\
\frac{\partial \Delta}{\partial G} & =\phi^{\prime}(G)-\lambda=0 .
\end{aligned}
$$


Proposition 2 The equilibrium allocations, and the supporting prices and taxes, in a closed economy are characterized by equations (1), (3), (5), (6) and

$$
\begin{aligned}
\phi^{\prime}(G) & =1, \\
-C^{\prime}(e) & =\varphi^{\prime}(E) .
\end{aligned}
$$

Observe that condition equation (9) yields the first-best value of $G$. This is not surprising. The assumption of inelastic demand implies that in a closed economy the output tax is non-distortionary. On the other hand, condition (10) which determines the second-best emission rule in a closed-economy, differs from the Pigouvian rule: $-C^{\prime}(e)$ is equated to $\varphi^{\prime}(E)$ rather than $2 \varphi^{\prime}(E)$. The reason for this is that each country equalizes the marginal private benefits of increasing emissions to its marginal social damage, with "social" being defined as the country's own residents only (the damage on the residents of the other country is ignored). We shall refer to this adjusted rule as the "internal" Pigouvian rule for combating emissions.

\section{International trade}

The previous section has shown that with transboundary pollution (but in the absence of trade), Nash-equilibrium environmental policies are inefficient. This does of course not come as a surprise. When markets open, the pollution remedies (namely the output and the emission taxes) themselves introduce an additional source of externality between countries. We have in mind fiscal externalities that arise when the value of one country's tax instrument affects the welfare of another country's residents by changing their consumer or producer prices, and their government's tax revenues (but that neither country takes the external effects of its fiscal policies into account in its optimization problem). Put differently, environmental levies may be subject to fiscal competition just like any other form of taxation. We now turn to the study of this fiscal externality and its interaction with the emission related externality. 


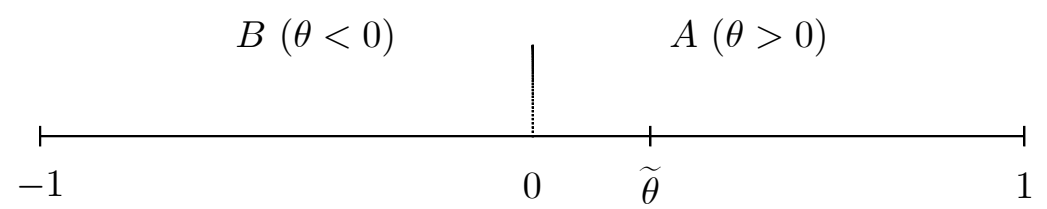

Figure 1. The countries, their inhabitants and the marginal consumer

With trade across borders, citizens of each country will be able to purchase the polluting good from the foreign country. While the physical characteristics of the homeand foreign-produced goods are identical, consumers have a preference for purchasing the home-produced goods. Let $\theta$ denote the inhabitants of $A$ and $B$, with $|\theta|$ determining $\theta$ 's disutility when consuming one unit of the foreign-produced good. Assume that $\theta$ is uniformly distributed over $[-1,1]$, with a negative $\theta$ indicating a resident of $B$ and a positive $\theta$ a resident of $A$; see Figure 1 .

Denote the utility level of a person in $j=A, B$ who purchases the polluting good produced in $i=A, B$ by $u_{i}^{j}$, the price he pays for the polluting good by $p_{i}^{j}$, the level of publicly-provided good in country $i=A, B$ by $G_{i}$, and the total (i.e. across both countries) emission level by $E$. We have, given the stipulated quasi-linear preferences,

$$
\left\{\begin{array}{l}
u_{j}^{j}=m-p_{j}^{j}+\phi\left(G_{j}\right)-\varphi(E), \\
u_{i}^{j}=m-p_{i}^{j}-\delta|\theta|+\phi\left(G_{j}\right)-\varphi(E), \quad \text { with } j \neq i,
\end{array}\right.
$$

where $\delta>0$ is a "dislike index".

When a resident of country $j$ buys the home-produced good, his net cost of purchasing one unit of the good is simply its consumer price, $p_{j}^{j}$. On the other hand, when he buys the foreign-produced good, he incurs a net (utility) cost of $p_{i}^{j}+\delta|\theta|$. We thus have, $u_{j}^{j}=u\left(p_{j}^{j}, G_{j}, E\right)$ and $u_{i}^{j}=u\left(p_{i}^{j}+\delta|\theta|, G_{j}, E\right)$. Denote the "marginal" consumer, i.e. the person who is just indifferent between buying home- or foreign-produced goods, by $\tilde{\theta}$. Note that all individuals to the left of $\tilde{\theta}$ buy the good from country $B$, and all 
the individuals to the right of $\tilde{\theta}$ buy the good from country $A$. The value of $E$ is then determined according to

$$
E=e_{B}(1+\tilde{\theta})+e_{A}(1-\tilde{\theta})
$$

regardless of which country $\tilde{\theta}$ lies in.

If the marginal consumer is a resident of $A(\tilde{\theta} \geq 0), u_{A}^{A}=u_{B}^{A} \Rightarrow u\left(p_{A}^{A}, G_{A}, E\right)=$ $u\left(p_{B}^{A}+\delta \tilde{\theta}, G_{A}, E\right)$. Consequently,

$$
\tilde{\theta}=\frac{p_{A}^{A}-p_{B}^{A}}{\delta}, \quad \text { if } \tilde{\theta} \geq 0
$$

Similarly, if $\tilde{\theta}$ is a resident of $B(\tilde{\theta}<0), u_{B}^{B}=u_{A}^{B} \Rightarrow u\left(p_{B}^{B}, G_{B}, E\right)=u\left(p_{A}^{B}-\delta \tilde{\theta}, G_{B}, E\right)$. Hence

$$
\tilde{\theta}=\frac{p_{A}^{B}-p_{B}^{B}}{\delta}, \quad \text { if } \tilde{\theta}<0 .
$$

Let $W_{i}(i=A, B)$ denote the utilitarian measure of welfare for country $i$. It is then the case that

$$
\begin{array}{rlrl}
W_{A} & =m+\phi\left(G_{A}\right)-\varphi(E)-(1-\tilde{\theta}) p_{A}^{A}-\int_{0}^{\tilde{\theta}}\left(p_{B}^{A}+\delta \theta\right) d \theta \\
& =m+\phi\left(G_{A}\right)-\varphi(E)-p_{A}^{A}+\frac{\delta}{2} \tilde{\theta}^{2}, & & \text { if } \tilde{\theta} \geq 0, \\
W_{A} & =m+\phi\left(G_{A}\right)-\varphi(E)-p_{A}^{A}, & & \text { if } \tilde{\theta}<0 .
\end{array}
$$

Similarly,

$$
\begin{array}{rlrl}
W_{B} & =m+\phi\left(G_{B}\right)-\varphi(E)-p_{B}^{B}, & & \text { if } \tilde{\theta} \geq 0, \\
W_{B} & =m+\phi\left(G_{B}\right)-\varphi(E)-(1+\tilde{\theta}) p_{B}^{B}-\int_{\tilde{\theta}}^{0}\left(p_{A}^{B}-\delta \theta\right) d \theta, \\
& =m+\phi\left(G_{B}\right)-\varphi(E)-p_{B}^{B}+\frac{\delta}{2} \tilde{\theta}^{2} . & & \text { if } \tilde{\theta}<0 .
\end{array}
$$

The emission tax, being levied on firms, is "origin-based". The output tax, on the other hand, may be either origin-based as well or levied on the basis of destination principle. The next sections studies the countries' choice of the tax regime, as well as the properties of the resulting equilibria. 


\section{Tax regime and tax rate competition: the two-stage game}

When deciding upon the overall tax policy, involving the choice of regimes and tax rates, it is natural to consider a sequential procedure (or game). We consider the following specification. In the first stage, the countries simultaneously choose their output tax regime $R_{i} \in\{O, D\} i=A, B$ ( $O$ stands for origin and $D$ for destination). Then, in the second stage, they (simultaneously) set their tax instruments $t$ and $\tau$, given the first-stage-selected output tax regime. We shall determine the subgame perfect Nash equilibrium of this game.

The game is solved by backward induction. We start by characterizing the tax competition equilibrium in the second stage subgames induced by the regime choice. These are: $(O, O),(D, D)$ and $(O, D)$; the fourth possible subgame $(D, O)$ is symmetrical to $(O, D)$. Observe that even though we concentrate on symmetrical equilibria, it is necessary to study the "asymmetric" second stage subgames. This is because a unilateral deviation from $(O, O)$ or $(D, D)$ yields an asymmetric second stage. To determine the subgame perfect equilibrium of the two stage game we thus have to determine the equilibrium payoffs in all possible second stage subgames, including the asymmetric regime cases.

\section{Tax rate competition: the second stage equilibrium}

\subsection{Origin-origin regime: the $(O, O)$ subgame}

Denote the producer price of $x$ in country $i$ by $q_{i}=C\left(e_{i}\right)-C^{\prime}\left(e_{i}\right) e_{i}$, and its commodity tax by $\tau_{i}$. Under origin principle of taxation, the purchasers (regardless of where they come from) pay the tax of the country in which the good is produced. Thus, under this principle, we have

$$
\left\{\begin{array}{l}
p_{j}^{j}=q_{j}+\tau_{j}, \\
p_{i}^{j}=q_{i}+\tau_{i}, \quad \text { with } j \neq i .
\end{array}\right.
$$


Hence $p_{i}^{j}=q_{i}+\tau_{i}=p_{i}^{i}$, and all purchasers of $x$ produced in $i$ pay the same price for it, regardless of where they reside. Denote this by $p_{i}$. It then follows from equations (13) and (14) that the expression for $\tilde{\theta}$ will be given by

$$
\tilde{\theta}=\frac{p_{A}-p_{B}}{\delta}
$$

regardless of which country sells the good at a higher price.

With $C\left(e_{i}\right)$ being the cost of producing one unit of the good in country $i$ and $p_{i}$ its consumer price, its production and sale will generate $p_{i}-C\left(e_{i}\right)$ in revenues for the government of $i$. Assuming the governments of $A$ and $B$ undertake no other expenditures or transfers except for $G$, which is produced at a fixed unit cost normalized at one, their budget constraints are, whether $p_{A} \geq p_{B}$ or $p_{A}<p_{B}$,

$$
\begin{aligned}
& G_{A}\left(p_{A}, e_{A} ; p_{B}\right)=\left[p_{A}-C\left(e_{A}\right)\right](1-\tilde{\theta}), \\
& G_{B}\left(p_{B}, e_{B} ; p_{A}\right)=\left[p_{B}-C\left(e_{B}\right)\right](1+\tilde{\theta}) .
\end{aligned}
$$

The following Proposition, proved in the Appendix, gives the characterizations for equilibrium output and emission taxes.

Proposition 3 The symmetric Nash equilibrium allocations, and the supporting prices and taxes, in the $(O, O)$ subgame are characterized (for $i=A, B)$ by equations (1), (3), (5), (6), and

$$
\begin{aligned}
G_{i} & =\delta \frac{\phi^{\prime}\left(G_{i}\right)-1}{\phi^{\prime}\left(G_{i}\right)}, \\
-C^{\prime}\left(e_{i}\right) & =\frac{\varphi^{\prime}(E)}{\phi^{\prime}\left(G_{i}\right)} .
\end{aligned}
$$

Observe that the rule for the determination of $G_{i}$ changes from that in the closedeconomy. Indeed, from (23), it follows that $\phi^{\prime}\left(G_{i}\right)>1$ and $G_{i}$ will be lower than its closed-economy solution (equal to its first-best value). On the other hand, equation (24) shows that the internal Pigouvian rule governing the determination of $e_{i}$ remains intact. We will come back to this in the next section. 


\subsection{Destination-destination regime: the $(D, D)$}

Under destination principle of taxation, the purchasers (whether they buy the homeor foreign-produced good) pay the tax of the country in which they reside. Under this principle, we have

$$
\left\{\begin{array}{l}
p_{j}^{j}=q_{j}+\tau_{j}, \\
p_{i}^{j}=q_{i}+\tau_{j}, \quad \text { with } j \neq i .
\end{array}\right.
$$

The marginal consumer is now given by

$$
\tilde{\theta}=\frac{q_{A}-q_{B}}{\delta}
$$

Contrasting this expression with (20), its counterpart in the origin-origin regime, it is apparent that consumer prices have been replaced by producer prices. Thus, under destination-destination regime, only $e_{i}$ determines who the marginal consumer is; $\tau_{j}$ has no impact. This property implies that emission taxes are the only potential instruments for tax competition. One can then easily establish that, regardless of which country $\tilde{\theta}$ resides in, the budget constraints for the governments of $A$ and $B$ are given by ${ }^{18}$

$$
\begin{aligned}
& G_{A}=-e_{A} C^{\prime}\left(e_{A}\right)(1-\tilde{\theta})+\tau_{A}, \\
& G_{B}-e_{B} C^{\prime}\left(e_{B}\right)(1+\tilde{\theta})+\tau_{B} .
\end{aligned}
$$

We prove the following proposition in the Appendix.

Proposition 4 The symmetric Nash equilibrium allocations, and the supporting prices and taxes, in the $(D, D)$ subgame are characterized (for $i=A, B$ ) by equations (1),

\footnotetext{
${ }^{18}$ For instance, if the marginal consumer is a resident of $A$, then $\tilde{\theta} \geq 0$ and $q_{A} \geq q_{B}$. Thus

$$
\begin{aligned}
G_{A} & =\left[p_{A}-C\left(e_{A}\right)\right](1-\tilde{\theta})+\tilde{\theta} \tau_{A}=-e_{A} C^{\prime}\left(e_{A}\right)(1-\tilde{\theta})+\tau_{A}, \\
G_{B} & =\left[p_{B}-C\left(e_{B}\right)\right](1+\tilde{\theta})-\tilde{\theta} \tau_{B}=-e_{B} C^{\prime}\left(e_{B}\right)(1+\tilde{\theta})+\tau_{B} .
\end{aligned}
$$
}

The corresponding expressions for $\tilde{\theta}<0$ are derived in a similar way. 
(3), (5), (6), and

$$
\begin{aligned}
\phi^{\prime}\left(G_{i}\right) & =1, \\
-C^{\prime}\left(e_{i}\right) & =\frac{\varphi^{\prime}(E)}{1+e_{i}^{2} C^{\prime \prime}\left(e_{i}\right) / \delta} .
\end{aligned}
$$

Observe that under the destination-destination solution, it is the rule for determining $G_{i}$, and its value, which remains unaffected by tax competition. ${ }^{19}$ The internal Pigouvian rule, on the other hand, changes.

\subsection{Origin-destination regime: the $(O, D)$ subgame}

Assume that $A$ chooses to set its output tax on the basis of origin principle, and $B$ on the basis of destination principle. The opposite case of $A$ choosing destination principle and $B$ origin principle is found in a similar manner.

We have:

$$
\begin{array}{ll}
p_{A}^{A}=q_{A}+\tau_{A} ; & p_{B}^{A}=q_{B} ; \\
p_{A}^{B}=q_{A}+\tau_{A}+\tau_{B} ; & p_{B}^{B}=q_{B}+\tau_{B} .
\end{array}
$$

Lack of symmetry between $p_{B}^{A}$ and $p_{A}^{B}$ suggests that in this case, we have to examine the solutions for $\tilde{\theta} \geq 0$ (marginal consumer in origin regime country) and $\tilde{\theta}<0$ (marginal consumer in destination regime country) separately.

Assume the marginal consumer is in the origin regime country $A$ so that $\tilde{\theta} \geq 0$. It follows from the expressions for $p_{A}^{A}$ and $p_{B}^{A}$ in (31) that,

$$
\tilde{\theta}=\frac{p_{A}^{A}-p_{B}^{A}}{\delta}=\frac{q_{A}+\tau_{A}-q_{B}}{\delta} .
$$

${ }^{19}$ This result is due to the assumption of an inelastic demand for the polluting good. Cremer and Gahvari (2004) show that when demand varies with price, an increase in the home country's output price imposes a negative fiscal externality on the foreign country. In turn, this implies that the home country's output tax is above its optimal price, and may lead to "too much" public goods in the home country. The fiscal externality arises because an increase in the home country's output tax may reduce the tax revenues of the foreign country. The mechanism for this is the reduction in the demand of the residents of the home country for the goods of the foreign country, caused by an increase in the price they have to pay for the foreign country's good (because of the increase in the output tax of the home country). Less purchases of foreign goods then leads to less emission tax revenues for the foreign country. Observe also that such a fiscal externality is not present with origin taxes. 
Observe that only $\tau_{A}$ appears in the formula for $\tilde{\theta}$. That is, the output tax affect the position of the marginal consumer only if it is levied on the basis of the origin principle. Moreover, given the pattern of taxation in the two countries,

$$
\begin{aligned}
G_{A} & =\left[p_{A}^{A}-C\left(e_{A}\right)\right](1-\tilde{\theta}), \\
G_{B} & =p_{B}^{B}-C\left(e_{B}\right)-\tilde{\theta} e_{B} C^{\prime}\left(e_{B}\right) .
\end{aligned}
$$

We prove the following proposition in the Appendix.

Proposition 5 The Nash equilibrium allocations, and the supporting prices and taxes, in the $(O, D)$ subgame are determined by equations (1), (3), (32), (33), (34), (12) and

$$
\begin{aligned}
& {\left[1-\tilde{\theta}-\frac{1}{\delta} \tau_{A}+\frac{1}{\delta} e_{B} C^{\prime}\left(e_{A}\right)\right] \phi^{\prime}\left(G_{A}\right)=1-\tilde{\theta}} \\
& -C^{\prime}\left(e_{A}\right)=\frac{\varphi^{\prime}(E)}{\phi^{\prime}\left(G_{A}\right)} \\
& \phi^{\prime}\left(G_{B}\right)=1 \\
& {\left[C^{\prime}\left(e_{B}\right)+\varphi^{\prime}(E)\right]\left[1+\tilde{\theta}+\frac{1}{\delta} e_{B}^{2} C^{\prime \prime}\left(e_{B}\right)\right]=e_{B} C^{\prime \prime}\left(e_{B}\right)\left[\frac{e_{A} \varphi^{\prime}(E)}{\delta}-\tilde{\theta}\right],}
\end{aligned}
$$

provided that the equilibrium value of $\tilde{\theta} \geq 0$.

Observe that country $A$ which adheres to origin principle continues to follow the internal Pigouvian rule. That is, the decision of country $A$ with respect to its emission is independent of the tax regime chosen by $B$. This is not the case with respect to $A$ 's choice of an output tax, as seen by equation (35). On the other hand, country $B$ which adheres to destination principle continues to set $G_{B}$ at its first-best value. In country $B$ 's case, it is the choice of $G_{B}$ which is independent of the other country's tax regime. Its choice of an emission tax, however, is affected by $A$ 's regime choice; see equation (38).

The case where $\tilde{\theta}<0$ is treated along the same line and presented in the Appendix. 


\section{Tax rate competition: equilibria versus closed-economy solution}

To understand how tax competition operates under each of the possible regime combinations, we compare the second stage equilibria to the closed-economy solution. In the absence of trade, the distinction between origin and destination taxes is plainly irrelevant. Consequently, one can use this solution as a common benchmark for comparison with the three possible tax rate competition equilibria.

Recall that the closed-economy solution for $i=A, B$ is characterized by:

$$
\begin{aligned}
& \phi^{\prime}\left(G_{i}\right)=1, \\
& -C^{\prime}\left(e_{i}\right)=\frac{\varphi^{\prime}(E)}{\phi^{\prime}\left(G_{i}\right)}=\varphi^{\prime}(E) .
\end{aligned}
$$

Under $(O, O)$, the characterization of the solution changes to

$$
\begin{aligned}
& \phi^{\prime}\left(G_{i}\right)>1, \\
& -C^{\prime}\left(e_{i}\right)=\frac{\varphi^{\prime}(E)}{\phi^{\prime}\left(G_{i}\right)}=\frac{\varphi^{\prime}(E)}{1+G_{i} /\left(\delta-G_{i}\right)} .
\end{aligned}
$$

The change in the first condition implies a change in the "rule" for determining $G_{i}$ (or alternatively $\tau_{i}$ ) as well as the equilibrium "level" of $G_{i}$. The new rule tells us that at the equilibrium value of $G_{i}$, its marginal valuation exceeds one (i.e. $M C P F_{i}>1$ ). Under origin taxes, a country can use its commodity tax to potentially lower the price of its output and to attract the other country's buyers. Thus the commodity tax is no-longer non-distortionary. This also explains why $M C P F_{i}>1$. The change in the "level" of $G_{i}$ follows the change in the "rule" and in the expected direction. With $\phi^{\prime}\left(G_{i}\right)>1$, the level of $G_{i}$ falls below its closed-economy solution (which is also first-best). This results in a lowering of the welfare for the countries' residents. On the other hand, given that $\tau_{i}-C^{\prime}\left(e_{i}\right) e_{i}=G_{i}$, the reduction in $G_{i}$ also implies a reduction in $\tau_{i}$ (for the same $e_{i}$ ). This leads to a reduction in $p_{i}$, mitigating the welfare-reduction due to the lowering of $G_{i}$. 
As far as the second condition is concerned, the "rule" for the determination of emission levels remains unchanged (in comparison to the closed-economy solution). However, the persistence of the rule does not translate into a non-changing pollution "level". With $\phi^{\prime}\left(G_{i}\right)>1$, the condition implies $-C^{\prime}\left(e_{i}\right)<\varphi^{\prime}(E)$, so that $e_{i}$ increases. This is also welfare reducing. Consequently, as compared to the closed-economy solution, welfare will definitely decline.

In the destination-destination regime taxes, we have for $i=A, B$,

$$
\begin{aligned}
& \phi^{\prime}\left(G_{i}\right)=1, \\
& -C^{\prime}\left(e_{i}\right)=\frac{\varphi^{\prime}(E)}{1+e_{i}^{2} C^{\prime \prime}\left(e_{i}\right) / \delta}<\varphi^{\prime}(E) .
\end{aligned}
$$

Now, the first condition remains unchanged from that in the closed-economy. This translates not just into an unchanged "rule" for the determination of $G_{i}$, but also in a level that remains unchanged. Thus, for the same $e_{i}$, there will be no change in $p_{i}$ (from $\left.G_{i}=p_{i}-C\left(e_{i}\right)\right)$ and no change in welfare either. Observe that with destination taxes, a country cannot use $\tau_{i}$ to influence the price of its output. This renders commodity taxes useless as an instrument for fiscal competition. This is also why the $M C P F_{i}$ remains unchanged at one.

In the case of the second condition, we now have $-C^{\prime}\left(e_{i}\right)<\varphi^{\prime}(E) / \phi^{\prime}\left(G_{i}\right)$. Hence the benefit of increasing pollution is set at a level below its marginal social damage. Moreover, the change in the rule translates into a change in the level, and in the expected direction. With $-C^{\prime}\left(e_{i}\right)<\varphi^{\prime}(E), e_{i}$ increases and welfare goes down. Essentially, what happens in this case is that, with the commodity tax not being a useful instrument for fiscal competition, the countries resort to the competition in emission taxes (leading to emission increases) as the means of lowering their prices and attracting the residents of the other country.

The above comparisons are with respect to the closed-economy solution. When comparing the equilibria under origin-origin and destination-destination taxes directly, 
we have that $G_{i}$ will always be lower (and sub-optimal) under the origin-origin regime. If this were the only change, one would of course expect that destination-destination regime to dominate origin-origin regime in terms of welfare. However, the second factor that comes into play is the level of pollution under the two regimes. Both regimes imply higher pollution levels than the closed-economy solution. The important point is that, compared to each other, either regime may result in a higher pollution level. This can potentially reverse the ranking of the two tax systems. The foregoing argument also suggests that whenever emissions are lower under destination-destination regime, this regime is the better one. The converse is not necessarily true. When emission levels are lower under origin-origin regime, it is still possible that the destination-destination regime will be better. The possibilities are demonstrated in the following section via examples.

Turning to the asymmetric tax regime, we have already seen that in this case the country which adheres to the origin principle continues to follow the internal Pigouvian rule regardless of the other country's regime $\left[-C^{\prime}\left(e_{A}\right)=\varphi^{\prime}(E) / \phi^{\prime}\left(G_{A}\right)\right]$. Similarly, we observed that the country which adheres to the destination principle chooses an efficient level of public goods regardless of the other country's regime $\left[\phi^{\prime}\left(G_{B}\right)=1\right]$. At the same time, the choice of $G_{A}$ and $e_{B}$ will be subject to distortions.

Finally, having characterized the equilibrium in all the possible second stage subgames, we are now in a position to examine the (first stage) regime choice. However, at this level of generality, an unambiguous ranking of the two countries' payoffs in the different induced subgames is not possible. To achieve some understanding of the first stage (strategic regime choice), we thus consider a series of illustrative numerical examples. Though restrictive, these examples are very effective in highlighting a number of interesting configurations that can effectively arise. 


\section{Tax regime competition: illustrative examples}

Consider the following specification:

$$
\begin{aligned}
& C\left(e_{i}\right)=\frac{b\left(1-e_{i}\right)^{2}}{2}, \\
& \phi\left(G_{i}\right)=a \ln \left(G_{i}\right), \\
& \varphi(E)=\varphi E .
\end{aligned}
$$

Tables 1-3 present three typical cases, based on different parameter values for $a, b, \delta$ and $\varphi$. In all the calculations, $m=4$. In Table $1,(D, D)$ is better for both $A$ and $B$ than $(O, O)$. As we lower the value of $a$, the ranking will change and $(O, O)$ will dominate $(D, D)$; see Table 2 . Nevertheless, $(D, D)$ remains the subgame perfect Nash equilibrium. This is very interesting in that it indicates the possibility of having a prisoner's dilemma game: Even though $(O, O)$ Pareto-dominates, $D$ is the dominant strategy for each country. ${ }^{20}$

As to the intuition behind the change in ranking, observe first that in Table 1, the $(D, D)$ regime is better despite its entailing a higher emission level than the $(O, O)$ regime. The dominance of the $(D, D)$ regime is thus due to its leaving the choice of $G$ undistorted, while $G$ is under-supplied under the $(O, O)$ regime. Now a reduction in $a$ implies a reduction in the consumers' valuation of the public good. This makes the under-provision of $G$ under $(O, O)$ to be less important. And with pollution being lower under $(O, O)$, this becomes the Pareto superior system.

The lowering the value of $a$ further will switch the equilibrium to $(O, O)$ as well. This is depicted in Table 3. Other parameter values also have an impact on the ranking and the type of equilibrium. Increasing $b$ from its value under Table 1 , makes both regimes to be more polluting, with the $(D, D)$ regime remaining as the more polluting

\footnotetext{
${ }^{20}$ In the reduced game obtained by backward induction.
} 
Table 1. Origin/origin; destination/destination; $\operatorname{origin}(A) / \operatorname{destination}(B)$

\begin{tabular}{|c|r|r|r|}
\hline & \multicolumn{3}{|c|}{$(a=1 ; b=4 ; \delta=40 ; \varphi=0.055)$} \\
\hline & Origin/Origin & Destination/Destination & Origin $(A) /$ Destination $(B)$ \\
\hline$G_{A}$ & 0.975610 & 1.0 & 0.974562 \\
\hline$G_{B}$ & 0.975610 & 1.0 & 1.0 \\
\hline$e_{A}$ & 0.986585 & 0.987472 & 0.986600 \\
\hline$e_{B}$ & 0.986585 & 0.987472 & 0.968490 \\
\hline$p_{A}^{A}$ & 0.975970 & 1.000310 & 0.996655 \\
\hline$p_{B}^{B}$ & 0.975970 & 1.000310 & 0.999323 \\
\hline$\tilde{\theta}$ & 0.0 & 0.0 & 0.021815 \\
\hline$p_{B}^{A}$ & & & 0.124056 \\
\hline$E$ & 1.973170 & 1.974940 & 1.954690 \\
\hline$W_{A}$ & 2.890810 & 2.891060 & 2.879590 \\
\hline$W_{B}$ & 2.890810 & 2.891060 & 2.893170 \\
\hline
\end{tabular}

Table 2. Origin/origin; destination/destination; origin $(A) / \operatorname{destination}(B)$

\begin{tabular}{|c|r|r|r|}
\hline & \multicolumn{3}{|c|}{$(a=0.1 ; b=4 ; \delta=40 ; \varphi=0.055)$} \\
\hline & Origin/Origin & Destination/Destination & Origin $(A) /$ Destination $(B)$ \\
\hline$G_{A}$ & 0.099751 & 1.0 & 0.099750 \\
\hline$G_{B}$ & 0.099751 & 1.0 & 0.1 \\
\hline$e_{A}$ & 0.986284 & 0.987472 & 0.986284 \\
\hline$e_{B}$ & 0.986284 & 0.987472 & 0.986428 \\
\hline$p_{A}^{A}$ & 0.100127 & 0.100314 & 0.100242 \\
\hline$p_{B}^{B}$ & 0.100127 & 0.100314 & 0.100306 \\
\hline$\tilde{\theta}$ & 0.0 & 0.0 & 0.001158 \\
\hline$p_{B}^{A}$ & & & 0.053920 \\
\hline$E$ & 1.972570 & 1.974940 & 1.972710 \\
\hline$W_{A}$ & 3.560870 & 3.560810 & 3.560780 \\
\hline$W_{B}$ & 3.560870 & 3.560810 & 3.560940 \\
\hline
\end{tabular}


Table 3. Origin/origin; destination/destination; origin $(A) / \operatorname{destination}(B)$

\begin{tabular}{|c|r|r|r|}
\hline & \multicolumn{3}{|c|}{$(a=0.05 ; b=4 ; \delta=40 ; \varphi=0.055)$} \\
\hline & Origin/Origin & Destination/Destination & Origin $(A) /$ Destination $(B)$ \\
\hline$G_{A}$ & 0.049938 & 0.05 & 0.049938 \\
\hline$G_{B}$ & 0.049938 & 0.05 & 0.05 \\
\hline$e_{A}$ & 0.986267 & 0.987472 & 0.986267 \\
\hline$e_{B}$ & 0.986267 & 0.987472 & 0.987460 \\
\hline$p_{A}^{A}$ & 0.050315 & 0.050314 & 0.050315 \\
\hline$p_{B}^{B}$ & 0.050315 & 0.050314 & 0.050314 \\
\hline$\tilde{\theta}$ & 0.0 & 0.0 & 0.000012 \\
\hline$p_{B}^{A}$ & & & 0.049847 \\
\hline$E$ & 1.972530 & 1.974940 & 1.973730 \\
\hline$W_{A}$ & 3.691350 & 3.691280 & 3.691280 \\
\hline$W_{B}$ & 3.691350 & 3.691280 & 3.691340 \\
\hline
\end{tabular}

regime. $^{21}$ It also remains the subgame perfect Nash equilibrium. Reducing $b$ from its value under Table 1, on the other hand, reduces pollution under both regimes. However, it also makes the $(D, D)$ regime less polluting that the $(O, O)$ regime. Consequently, $(D, D)$ regimes remains Pareto superior to $(O, O)$ regime as well as being the subgame perfect Nash equilibrium. The nature and the ranking of the equilibria thus remains the same as that in Table 1.

The same is true with respect to possible changes in $\delta$, the "dislike index" of foreign products. Observe that at very high values of $\delta$, the two regimes approach the closed-economy solution and thus coincide. Lowering $\delta$, on the other hand, lowers the equilibrium value of $G$ under the $(O, O)$ system making its under-provision more acute. Consequently, the $(D, D)$ regime retains its superiority.

Finally, we observe that the effect of changing the marginal social damage of emissions on the ranking and the nature of the equilibria is, unlike those of the changes in $a, b$ and $\delta$, non-monotonic. Initially, as we increase the value of $\varphi$ from its value

\footnotetext{
${ }^{21}$ In fact, as $b \rightarrow \infty$, under both regimes $e \rightarrow 1$, and the under-provision of $G$ in the origin-origin system remains as the sole determining factor in its being the Pareto-inferior outcome.
} 
Table 4. Origin/origin; destination/destination; origin $(A) / \operatorname{destination}(B)$

\begin{tabular}{|c|r|r|r|}
\hline & \multicolumn{3}{|c|}{$(a=1 ; b=4 ; \delta=40 ; \varphi=0.25)$} \\
\hline & Origin/Origin & Destination/Destination & Origin $(A) /$ Destination $(B)$ \\
\hline$G_{A}$ & 0.975610 & 1.0 & 0.974801 \\
\hline$G_{B}$ & 0.975610 & 1.0 & 1.0 \\
\hline$e_{A}$ & 0.939024 & 0.942600 & 0.939075 \\
\hline$e_{B}$ & 0.939024 & 0.942600 & 0.927312 \\
\hline$p_{A}^{A}$ & 0.983046 & 1.006590 & 1.000090 \\
\hline$p_{B}^{B}$ & 0.983046 & 1.006590 & 1.005710 \\
\hline$\tilde{\theta}$ & 0.0 & 0.0 & 0.017998 \\
\hline$p_{B}^{A}$ & & & 0.280183 \\
\hline$E$ & 1.878050 & 1.885200 & 1.866180 \\
\hline$W_{A}$ & 2.522750 & 2.522110 & 2.514320 \\
\hline$W_{B}$ & 2.522750 & 2.522110 & 2.527740 \\
\hline
\end{tabular}

under Table 1, the $(O, O)$ system will not only keep its less-polluting property, but it also becomes the Pareto superior outcome. Nevertheless, $(D, D)$ remains the subgame perfect Nash equilibrium. Again, we have another example of the prisoner's dilemma game. This situation is depicted in Table 4. However, as we increase $\varphi$ further, the $(O, O)$ regime becomes more polluting and Pareto-inferior; $(D, D)$ remains the subgame perfect Nash equilibrium. This situation is depicted in Table 5.

\section{Conclusion}

This paper has studied the design of second-best output and emissions taxes in a global economy with an atmospheric externality, while endogenizing the choice of the output tax regime. It has modeled the choice of the tax regime and the tax rates (output and emission) as a sequential game. In the first stage, the countries simultaneously choose their output tax regime (emission taxes, almost by definition, must be origin based.) In the second stage, they (simultaneously) set their tax instruments, given the first-stage-selected output tax regime. The subgame perfect Nash equilibrium of this 
Table 5. Origin/origin; destination/destination; origin $(A) / \operatorname{destination}(B)$

\begin{tabular}{|c|r|r|r|}
\hline & \multicolumn{3}{|c|}{$(a=1 ; b=4 ; \delta=40 ; \varphi=2.5)$} \\
\hline & Origin/Origin & Destination/Destination & Origin $(A) /$ Destination $(B)$ \\
\hline$G_{A}$ & 0.975610 & 1.0 & 0.975946 \\
\hline$G_{B}$ & 0.975610 & 1.0 & 1.0 \\
\hline$e_{A}$ & 0.390244 & 0.384086 & 0.390034 \\
\hline$e_{B}$ & 0.390244 & 0.384086 & 0.384077 \\
\hline$p_{A}^{A}$ & 1.719210 & 1.758700 & 1.720440 \\
\hline$p_{B}^{B}$ & 1.719210 & 1.758700 & 1.758360 \\
\hline$\ddot{\theta}$ & 0.0 & 0.0 & 0.0003868 \\
\hline$p_{B}^{A}$ & & & 1.704970 \\
\hline$E$ & 0.780488 & 0.768172 & 0.774108 \\
\hline$W_{A}$ & 0.304873 & 0.320870 & 0.319943 \\
\hline$W_{B}$ & 0.304873 & 0.320870 & 0.306373 \\
\hline
\end{tabular}

game constitutes the countries' output tax regimes, and the values of their emission and output taxes. Six general lessons have emerged.

First, under origin-origin regime, the principle of targeting that governs taxation of outputs and emissions in closed economies continues to apply. Output taxes are levied for optimal tax considerations and, in open economies, for the purpose of tax competition as well; emission taxes are used solely for control of pollution. Specifically, the competition in output tax results in the distortion of the "rule" for the provision of public goods. This distortion is translated into an under-provision of public goods (as compared to their closed-economy level which is also the first-best level). The characterization of the emission tax remains the same as in the closed economy, and equal to the marginal social damage of emissions (nationally). Nevertheless, because the public good is provided sub-optimally, emissions exceed their closed-economy level.

Second, because the output tax is not an effective instrument for tax competition under destination-destination regime, it causes the principle of targeting to break down. Emission taxes are used not only to control pollution, but for tax competition as well. 
Specifically, the absence of competition in output taxes implies that the provision of public goods remains first-best optimal (both in terms of rule as well as level). The competition in emission taxes implies that the emission tax is set below the marginal social damage of emissions (nationally), and emissions are pushed above their closedeconomy level.

Third, either tax regime may Pareto-dominate the other. The destination-destination regime tends to be better because it results in the the optimal provision of public goods. However, a substantially higher level of pollution under this regime may reverse that ranking. This is more likely to occur, the lower is the consumers' valuation of public goods relative to private goods. This reduces the welfare implications of the suboptimal provision of public goods under the origin-origin regime. Fourth, either the destination-destination or the origin-origin regime may constitute the subgame perfect Nash equilibrium of the two-stage game between the two countries. Fifth, the likelihood of the origin-origin regime to be the equilibrium outcome of the game increases as the utility of the public goods relative to the private goods decreases. Sixth, it is possible to have a prisoner's dilemma game where the origin-origin regime Pareto-dominates but the choice of the destination regime is the dominant strategy for each country. 


\section{Appendix}

Proof of Proposition 3: Partially differentiate equation (15) with respect $\tau_{A}$ and $t_{A}$, and equation (17) with respect to $\tau_{B}$ and $t_{B}$. We have

$$
\begin{aligned}
\frac{\partial W_{A}}{\partial \tau_{A}} & =-\frac{\partial p_{A}^{A}}{\partial \tau_{A}}+\delta \tilde{\theta} \frac{\partial \tilde{\theta}}{\partial \tau_{A}}+\phi^{\prime}\left(G_{A}\right) \frac{\partial G_{A}}{\partial \tau_{A}}-\varphi^{\prime}(E) \frac{\partial E}{\partial \tau_{A}}=0 \\
\frac{\partial W_{A}}{\partial t_{A}} & =-\frac{1}{C^{\prime \prime}\left(e_{A}\right)}\left[-\frac{\partial p_{A}^{A}}{\partial e_{A}}+\delta \tilde{\theta} \frac{\partial \tilde{\theta}}{\partial e_{A}}+\phi^{\prime}\left(G_{A}\right) \frac{\partial G_{A}}{\partial e_{A}}-\varphi^{\prime}(E) \frac{\partial E}{\partial e_{A}}\right]=0 \\
\frac{\partial W_{B}}{\partial \tau_{B}} & =-\frac{\partial p_{B}^{B}}{\partial \tau_{B}}+\phi^{\prime}\left(G_{B}\right) \frac{\partial G_{B}}{\partial \tau_{B}}-\varphi^{\prime}(E) \frac{\partial E}{\partial \tau_{B}}=0, \\
\frac{\partial W_{B}}{\partial t_{B}} & =-\frac{1}{C^{\prime \prime}\left(e_{B}\right)}\left[-\frac{\partial p_{B}^{B}}{\partial e_{B}}+\phi^{\prime}\left(G_{B}\right) \frac{\partial G_{B}}{\partial e_{B}}-\varphi^{\prime}(E) \frac{\partial E}{\partial e_{B}}\right]=0 .
\end{aligned}
$$

Next, we have from equation (3) that, for $i=A, B, \partial p_{i}^{i} / \partial \tau_{i}=1, \partial p_{i}^{i} / \partial e_{i}=-e_{i} C^{\prime \prime}\left(e_{i}\right)$. Moreover, from (20), $\partial \tilde{\theta} / \partial \tau_{A}=1 / \delta, \partial \tilde{\theta} / \partial e_{A}=-e_{A} C^{\prime \prime}\left(e_{A}\right) / \delta, \partial \tilde{\theta} / \partial \tau_{B}=-1 / \delta, \partial \tilde{\theta} / \partial e_{B}$ $=e_{B} C^{\prime \prime}\left(e_{B}\right) / \delta$. Differentiate equations (27) and (12) partially with respect to $\tau_{A}, e_{A}$, and equations (28) and (12) partially with respect to $\tau_{B}, e_{B}$. We have

$$
\begin{aligned}
\frac{\partial G_{A}}{\partial \tau_{A}} & =1-\tilde{\theta}-\frac{1}{\delta}\left[p_{A}-C\left(e_{A}\right)\right], \\
\frac{\partial G_{A}}{\partial e_{A}} & =\left[-e_{A} C^{\prime \prime}\left(e_{A}\right)-C^{\prime}\left(e_{A}\right)\right](1-\tilde{\theta})+\frac{1}{\delta} e_{A} C^{\prime \prime}\left(e_{A}\right)\left[p_{A}-C\left(e_{A}\right)\right], \\
\frac{\partial E}{\partial \tau_{A}} & =\frac{1}{\delta}\left(e_{B}-e_{A}\right), \\
\frac{\partial E}{\partial e_{A}} & =1-\tilde{\theta}-\frac{1}{\delta} e_{A} C^{\prime \prime}\left(e_{A}\right)\left(e_{B}-e_{A}\right), \\
\frac{\partial G_{B}}{\partial \tau_{B}} & =1+\tilde{\theta}-\frac{1}{\delta}\left[p_{B}-C\left(e_{B}\right)\right], \\
\frac{\partial G_{B}}{\partial e_{B}} & =\left[-e_{B} C^{\prime \prime}\left(e_{B}\right)-C^{\prime}\left(e_{B}\right)\right](1+\tilde{\theta})+\frac{1}{\delta} e_{B} C^{\prime \prime}\left(e_{B}\right)\left[p_{B}-C\left(e_{B}\right)\right], \\
\frac{\partial E}{\partial \tau_{B}} & =-\frac{1}{\delta}\left(e_{B}-e_{A}\right), \\
\frac{\partial E}{\partial e_{B}} & =1+\tilde{\theta}+\frac{1}{\delta} e_{B} C^{\prime \prime}\left(e_{B}\right)\left(e_{B}-e_{A}\right) .
\end{aligned}
$$

Evaluating these derivatives at $\tilde{\theta}=0$, substituting the resulting values in (A1)-(A4) and simplifying yield equations (23)-(24) in the text. 
Proof of Proposition 4: we have from equation (2) that, as with the origin-origin case,for $i=A, B, \partial p_{i}^{i} / \partial \tau_{i}=1, \partial p_{i}^{i} / \partial e_{i}=-e_{i} C^{\prime \prime}\left(e_{i}\right)$. Moreover, from (26)- (20), $\partial \tilde{\theta} / \partial \tau_{A}=0, \partial \tilde{\theta} / \partial e_{A}=-e_{A} C^{\prime \prime}\left(e_{A}\right) / \delta, \partial \tilde{\theta} / \partial \tau_{B}=0, \partial \tilde{\theta} / \partial e_{B}=e_{B} C^{\prime \prime}\left(e_{B}\right) / \delta$. It then follows from partial differentiation of equations (21) and (12) with respect to $\tau_{A}, e_{A}$, and equations (22) and (12) with respect to $\tau_{B}, e_{B}$, that

$$
\begin{aligned}
\frac{\partial G_{A}}{\partial \tau_{A}} & =1, \\
\frac{\partial G_{A}}{\partial e_{A}} & =\left[-e_{A} C^{\prime \prime}\left(e_{A}\right)-C^{\prime}\left(e_{A}\right)\right](1-\tilde{\theta})-\frac{1}{\delta} e_{A}^{2} C^{\prime}\left(e_{A}\right) C^{\prime \prime}\left(e_{A}\right), \\
\frac{\partial E}{\partial \tau_{A}} & =0, \\
\frac{\partial E}{\partial e_{A}} & =1-\tilde{\theta}-\frac{1}{\delta} e_{A} C^{\prime \prime}\left(e_{A}\right)\left(e_{B}-e_{A}\right), \\
\frac{\partial G_{B}}{\partial \tau_{B}} & =1, \\
\frac{\partial G_{B}}{\partial e_{B}} & =\left[-e_{B} C^{\prime \prime}\left(e_{B}\right)-C^{\prime}\left(e_{B}\right)\right](1+\tilde{\theta})-\frac{1}{\delta} e_{B}^{2} C^{\prime}\left(e_{B}\right) C^{\prime \prime}\left(e_{B}\right), \\
\frac{\partial E}{\partial \tau_{B}} & =0, \\
\frac{\partial E}{\partial e_{B}} & =1+\tilde{\theta}+\frac{1}{\delta} e_{B} C^{\prime \prime}\left(e_{B}\right)\left(e_{B}-e_{A}\right) .
\end{aligned}
$$

Evaluating these derivatives at $\tilde{\theta}=0$, substituting the resulting values in (A1)-(A4) and simplifying, yield equations (29)-(30) in the text.

Proof of Proposition 5: Differentiate equations (33) and (12) partially with respect to $\tau_{A}, e_{A}$, and equations (34) and (12) partially with respect to $\tau_{B}, e_{B}$. We have

$$
\begin{aligned}
\frac{\partial G_{A}}{\partial \tau_{A}} & =1-\tilde{\theta}-\frac{1}{\delta}\left[p_{A}^{A}-C\left(e_{A}\right)\right] \\
\frac{\partial G_{A}}{\partial e_{A}} & =\left[-e_{A} C^{\prime \prime}\left(e_{A}\right)-C^{\prime}\left(e_{A}\right)\right](1-\tilde{\theta})+\frac{1}{\delta} e_{A} C^{\prime \prime}\left(e_{A}\right)\left[p_{A}^{A}-C\left(e_{A}\right)\right], \\
\frac{\partial E}{\partial \tau_{A}} & =\frac{1}{\delta}\left(e_{B}-e_{A}\right), \\
\frac{\partial E}{\partial e_{A}} & =1-\tilde{\theta}-\frac{1}{\delta} e_{A} C^{\prime \prime}\left(e_{A}\right)\left(e_{B}-e_{A}\right),
\end{aligned}
$$




$$
\begin{aligned}
\frac{\partial G_{B}}{\partial \tau_{B}} & =1 \\
\frac{\partial G_{B}}{\partial e_{B}} & =-(1+\tilde{\theta})\left[e_{B} C^{\prime \prime}\left(e_{B}\right)+C^{\prime}\left(e_{B}\right)\right]-\frac{1}{\delta} e_{B}^{2} C^{\prime}\left(e_{B}\right) C^{\prime \prime}\left(e_{B}\right) \\
\frac{\partial E}{\partial \tau_{B}} & =0 \\
\frac{\partial E}{\partial e_{B}} & =1+\tilde{\theta}+\frac{1}{\delta} e_{B} C^{\prime \prime}\left(e_{B}\right)\left(e_{B}-e_{A}\right) .
\end{aligned}
$$

Substituting from above in (A1)-(A4) and simplifying, yield equations (35)-(38) in the text.

The $(O, D)$ subgame with $\tilde{\theta}<0$ :

Assume that the marginal consumer is in country $B$ (with a destination regime). It now follows from the expressions for $p_{A}^{B}$ and $p_{B}^{B}$ in (31) that,

$$
\tilde{\theta}=\frac{p_{A}^{B}-p_{B}^{B}}{\delta}=\frac{q_{A}+\tau_{A}-q_{B}}{\delta} .
$$

And, with the pattern of taxation in the two countries,

$$
\begin{aligned}
G_{A} & =\left[p_{A}^{A}-C\left(e_{A}\right)\right](1-\tilde{\theta}), \\
G_{B} & =\left[p_{B}^{B}-C\left(e_{B}\right)\right](\tilde{\theta}+1)-\tilde{\theta} \tau_{B}=p_{B}^{B}-C\left(e_{B}\right)-\tilde{\theta} e_{B} C^{\prime}\left(e_{B}\right) .
\end{aligned}
$$

This is the same specification as for $\tilde{\theta}>0$. As previously, $\tilde{\theta}$ is independent of $\tau_{B}$.

Differentiate equation (16) with respect to $\tau_{A}, t_{A}$, and equation (18) with respect to $\tau_{B}, t_{B}$. We have

$$
\begin{aligned}
\frac{\partial W_{A}}{\partial \tau_{A}} & =-\frac{\partial p_{A}^{A}}{\partial \tau_{A}}+\phi^{\prime}\left(G_{A}\right) \frac{\partial G_{A}}{\partial \tau_{A}}-\varphi^{\prime}(E) \frac{\partial E}{\partial \tau_{A}}=0 \\
\frac{\partial W_{A}}{\partial e_{A}} & =-\frac{1}{C^{\prime \prime}\left(e_{A}\right)}\left[-\frac{\partial p_{A}^{A}}{\partial e_{A}}+\phi^{\prime}\left(G_{A}\right) \frac{\partial G_{A}}{\partial e_{A}}-\varphi^{\prime}(E) \frac{\partial E}{\partial e_{A}}\right]=0 \\
\frac{\partial W_{B}}{\partial \tau_{B}} & =-\frac{\partial p_{B}^{B}}{\partial \tau_{B}}+\delta \tilde{\theta} \frac{\partial \tilde{\theta}}{\partial \tau_{B}}+\phi^{\prime}\left(G_{B}\right) \frac{\partial G_{B}}{\partial \tau_{B}}-\varphi^{\prime}(E) \frac{\partial E}{\partial \tau_{B}}=0 \\
\frac{\partial W_{B}}{\partial e_{B}} & =-\frac{1}{C^{\prime \prime}\left(e_{B}\right)}\left[-\frac{\partial p_{B}^{B}}{\partial e_{B}}+\delta \tilde{\theta} \frac{\partial \tilde{\theta}}{\partial e_{B}}+\phi^{\prime}\left(G_{B}\right) \frac{\partial G_{B}}{\partial e_{B}}-\varphi^{\prime}(E) \frac{\partial E}{\partial e_{B}}\right]=0 .
\end{aligned}
$$


Next differentiate equations (A6) and (12) partially with respect to $\tau_{A}, e_{A}$, and equations (A7) and (12) partially with respect to $\tau_{B}, e_{B}$. The expressions for these derivatives will be equivalent to those we derived for $\tilde{\theta}>0$. Substituting in (A8)-(A11) and simplifying, yield equations (A12)-(A15) below. We have

Proposition 6 The Nash equilibrium allocations, and the supporting prices and taxes, in the $(O, D)$ subgame are determined by equations (1), (3), (A5), (A6), (A7), (12) and

$$
\begin{aligned}
& {\left[1-\tilde{\theta}-\frac{1}{\delta} \tau_{A}+\frac{1}{\delta} e_{B} C^{\prime}\left(e_{A}\right)\right] \phi^{\prime}\left(G_{A}\right)=1,} \\
& -C^{\prime}\left(e_{A}\right)=\frac{\varphi^{\prime}(E)}{\phi^{\prime}\left(G_{A}\right)} \\
& \phi^{\prime}\left(G_{B}\right)=1 \\
& {\left[C^{\prime}\left(e_{B}\right)+\varphi^{\prime}(E)\right]\left[1+\tilde{\theta}+\frac{1}{\delta} e_{B}^{2} C^{\prime \prime}\left(e_{B}\right)\right]=e_{B} C^{\prime \prime}\left(e_{B}\right) \frac{e_{A} \varphi^{\prime}(E)}{\delta},}
\end{aligned}
$$

provided that in equilibrium $\tilde{\theta}<0$. 


\section{References}

Antweiler, W., Copeland, B.R. and M.S. Taylor (2001) "Is free trade good for the environment?," American Economic Review, 91, 877-908.

Atkinson, A.B. and N.H. Stern (1974) "Pigou, taxation and public goods," Review of Economic Studies, 41, 119-128.

Barrett, S. (1994) "Strategic environmental policy and international trade," Journal of Public Economics, 54, 325-338.

Chichilinisky, G. (1994) "North-south trade and the global environment," American Economic Review, 84, 851-874.

Conrad, K. (1993) "Taxes and subsidies for pollution-intensive industries as trade policy," Journal of Environmental Economics and Management, 25, 121-135.

Copeland, B.R. and M.S. Taylor (1995) "Trade and transboundary pollution," American Economic Review, 85, 716-737.

Cremer, H., and F. Gahvari (2001) "Second-best taxation of emissions and polluting goods," Journal of Public Economics, 80, 169-197.

Cremer, H. and F. Gahvari (2004) "Which border taxes? Output and emission taxes under origin and destination regimes," mimeo.

Cremer, H., V. Fourgeaud, M. Leite Monteiro, M. Marchand and P. Pestieau (1996) "Mobility and redistribution: A survey of the literature," Public Finance, 51, $325-352$.

Haufler, A. (2001) Taxation in a Global Economy. Cambridge: Cambridge University Press.

Kanbur, R. and M. Keen (1993) "Jeux sans frontières: Tax competition and tax coordination when countries differ in size," American Economic Review, 83, 877-892.

Karp, L., Sacheti, S. and J. Zhao (2001) "Common ground between free-traders and environmentalists," International Economic Review, 42, 617-647.

Keen, M. and S. Lahiri (1998) "The comparison between destination and origin principles under imperfect competition," Journal of International Economics, 45, 323-350.

Kennedy, P.W. (1994) "Equilibrium pollution taxes in open economies with imperfect competition," Journal of Environmental Economics and Management, 27, 49-63.

Lockwood, B. (1993) "Commodity tax competition under destination and origin principles," Journal of Public Economics, 52, 141-162.

Lockwood, B. (2001) "Tax competition and tax co-ordination under destination and original principles: a synthesis," Journal of Public Economics, 81, 279-319. 
Lockwood, B., de Meza, D. and G. Myles (1994) "When are origin and destination regimes equivalent?," International Tax and Public Finance, 1, 5-25.

Mintz, J. and H. Tulkens (1986) "Commodity tax competition between member states of a federation: equilibrium and efficiency," Journal of Public Economics, 29, 133-172.

Wellisch, D. (2000) Theory of Public Finance in a Federal State. Cambridge: Cambridge University Press. 